\title{
Properties of the Surface Alloyed AISI 1020 Steel with $\mathrm{Fe}_{(15-x)} \mathrm{Mo}_{x} \mathrm{~B}_{5}$ Alloy
}

\author{
E. Abakay, S. Sen And U. Sen* \\ Sakarya University, Engineering Faculty, Department of Metallurgy and Materials Engineering \\ Esentepe Campus, 54187 Sakarya, Turkey
}

\begin{abstract}
It is now well established that considerable improvement in the mechanical/chemical properties of near surface regions of materials can be achieved by the process of surface alloying. In the present study, surface alloying treatment with molybdenum and boron on the surface of the AISI 1020 steel was realized by the technique of tungsten inert gas welding. Ferrous boron alloy and ferrous molybdenum were used for surface alloying treatment. Before the treatment, ferrous alloys were grinded and sieved to be smaller than $45 \mu \mathrm{m}$. Prepared powder was pressed on the steel substrate and melted by tungsten inert gas welding for surface alloying. Coated layers formed on the steel substrate were investigated using optical and scanning electron microscopy, X-ray diffraction analysis and Vickers microhardness testers. It was shown that surface alloyed layer has composite structure including steel matrix and well distributed boride phases. Borides formed in the coated layers have a small precipitated structure and distributed in the grain boundaries as continuous phases. X-ray diffraction analyses show that coated layers include $\mathrm{Fe}_{2} \mathrm{~B}, \mathrm{Fe}_{13} \mathrm{Mo}_{2} \mathrm{~B}_{5}, \mathrm{Mo}_{2} \mathrm{FeB}_{4}$, and iron.
\end{abstract}

DOI: 10.12693 /APhysPolA.125.584

PACS: 52.77.Fv, 81.40.Cd, 81.40.Ef, 81.05.Je, 81.40.-z

\section{Introduction}

The need for improved wear resistance against abrasive tools to cope with ever-increasing demand for higher productivity has led to numerous developments in the field of wear resistant materials vs. abrasive materials. These activities have been mainly directed towards improvement of the alloys including high hardness phases in the surface alloyed layers and adhesion of surface alloyed layer to the matrix, along with increase of its strength and wear resistance [1].

The hard facing alloys obtained using high-energy density sources such as electron beam welding, plasma arc and laser have been widely applied to enhance the wear and corrosion resistance of material surface $[2-5]$. Tungsten inert gas (TIG) remelting is cheap and well known. However, it suffers from a number of disadvantages in comparison with laser remelting. TIG electrodes require adjustment prior to melting, and are consumed to a small extent during melting. It is more difficult to control the location and energy of a TIG arc to produce a prescribed melted pattern and treatment depth [6]. The gas tungsten arc welding (TIG) process is used when a good weld appearance and a high quality of the weld are required. In this process, an electric arc is formed between a tungsten electrode and the base metal. The arc region is protected by a kind of inert gas or a mixture of inert gases. The tungsten electrode is heated to temperatures high enough for the emission of the necessary electrons for the operation of the arc [7]. Molybdenum and iron

*corresponding author; e-mail: ugursen@sakarya.edu.tr are a strong boride-forming element, which forms stabile borides like $\mathrm{FeB}, \mathrm{Fe}_{2} \mathrm{~B}, \mathrm{Mo}_{2} \mathrm{~B}, \mathrm{MoB}, \mathrm{Mo}_{2} \mathrm{~B}_{5}, \mathrm{Fe}_{13} \mathrm{Mo}_{2} \mathrm{~B}_{5}$, $\mathrm{Fe}_{14} \mathrm{MoB}_{5}, \mathrm{FeMo}_{2} \mathrm{~B}_{2}, \mathrm{FeMo}_{8} \mathrm{~B}_{11}$ etc. [8-10]. These compounds have high melting temperature, hardness and wear resistance like $\mathrm{Zr}, \mathrm{Ti}$ and $\mathrm{Cr}$ borides [9-10]. There is not enough study about the $\mathrm{Fe}-\mathrm{Mo}-\mathrm{B}$ alloys used for surface alloying treatments.

In this investigation, TIG process is used as a high energy density beam to form a high molybdenum $\mathrm{Fe}-\mathrm{Mo}-\mathrm{B}$ hard surface on the AISI 1020 steel with a powder mixtures consisting of ferrous molybdenum, ferrous boron and iron. Main objective of the study is structural characterization of the surface alloyed steels with $\mathrm{Fe}_{(15-x)} \mathrm{Mo}_{x} \mathrm{~B}_{5}$, where $x=1,3$, and 5 (by at.\%) alloys.

\section{Experimental procedure}

The substrate material used for surface alloying was prepared from AISI 1020 steel plates with the dimensions of $25 \mathrm{~mm} \times 75 \mathrm{~mm} \times 5 \mathrm{~mm}$. The nominal chemical composition of the AISI 1020 steel (in wt\%) was as follows: $0.21 \% \mathrm{C}, 0.18 \% \mathrm{Si}, 0.52 \% \mathrm{Mn}$, and balance $\mathrm{Fe}$. Before the surface alloying, these specimens were ground and cleaned with acetone to remove any oxide and grease and then dried with compressed air. The nominal composition of ferrous boron alloys used in the study (wt\%) was as follows: $19.63 \% \mathrm{~B}, 0.44 \% \mathrm{C}, 0.05 \% \mathrm{Al}, 0.98 \% \mathrm{Si}$, and balance Fe. The nominal composition of ferrous molybdenum alloys used in the study (wt\%) was as follows: $63.62 \% \mathrm{Mo}, 0.5 \% \mathrm{Cu}, 1.51 \% \mathrm{Si}, 0.09 \% \mathrm{~S}, 0.98 \% \mathrm{C}$, and balance Fe. Ferrous boron and molybdenum were grounded by ring grinder and sieved to be $45 \mu \mathrm{m}$ particle sizes. Figure 1 shows the scanning electron microscopy (SEM) images of the ferrous boron and ferrous molybdenum powders used in the surface alloying treatment. 


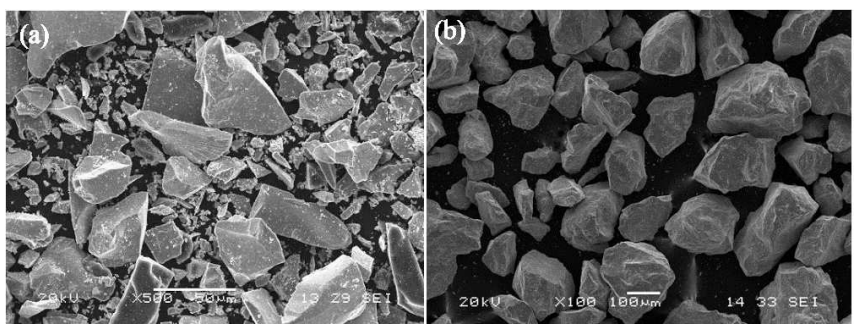

Fig. 1. SEM images of (a) ferrous boron and (b) ferrous molybdenum powders.

TIG welding was realized by an electric power supply in which the welding torch was moved back and forth at a constant speed. TIG welding was applied to melt the substrate and alloy filler. The welding was realized with $2.4 \mathrm{~mm}$ type $\mathrm{W}-2$ pct ThO electrode and with an angle of $70^{\circ}$ at $110 \mathrm{~A}$ current density and $20 \mathrm{~V}$ potential under the $\mathrm{Ar}(99.9 \% \mathrm{Ar})$ atmosphere at the travel speeds of $60 \mathrm{~mm} / \mathrm{min}$.

An X-ray diffractometer (Rigaku XRD/D/MAX/ $2200 / \mathrm{PC}$ ) with $\mathrm{Cu} K_{\alpha}$ radiation was used to analyze the constituent phases in the microstructure. Metallographic analysis was performed by optical microscopy (OM) to the samples which were replaced in resin, ground on silicon carbide papers to 1200 grit, and then progressively polished with $0.3 \mu \mathrm{m} \mathrm{Al}_{2} \mathrm{O}_{3}$ paste.

The etchant was selected as ASTM 209 [11]. The microstructures of the cross-section of the alloyed layers were observed by using OM (NICKON EPIPHOT), the hardness of the phases formed in the alloyed layer and transition zone and matrix were measured by using Future-Tech FM 700 microhardness tester.

\section{Results and discussion}

Surface alloying modification by ferrous boron and ferrous molybdenum filler alloys was realized by means of TIG welding. In the process, a thin surface layer of the base metal were simultaneously melted together with ferrous alloys and then rapidly solidified to form a dense coating bonded to the base metal. Surface alloyed layer consists of iron, boron, and molybdenum. Figure 2 shows the cross-sectional micrographs of the alloyed layers of the $\mathrm{Fe}_{(15-x)} \mathrm{Mo}_{x} \mathrm{~B}_{5}$ alloy where $x=1,3$, and 5 (by at.\%) alloys. The thickness of the hard-faced layer ranged from 1 to $3 \mathrm{~mm}$. The melted surfaces of the surface alloyed steel have smooth and rippled surface topography.

Figure 3 shows the XRD spectra of the surface alloyed layers of the steel with $\mathrm{Fe}_{(15-x)} \mathrm{Mo}_{x} \mathrm{~B}_{5}$ alloys. The phases formed in the surface alloyed layers consist of $\mathrm{Fe}_{2} \mathrm{~B}, \mathrm{Fe}_{13} \mathrm{Mo}_{2} \mathrm{~B} 5, \mathrm{Mo}_{2} \mathrm{FeB}_{4}$, and iron phases.

Figure 2 and Fig. $4 \mathrm{a}-\mathrm{c}$ showed that microstructural examinations of the alloyed surface layers include three distinct regions taking place on the cross-section of the surface alloyed steels which were: alloyed layers consisting of boride phases on the grain boundaries, marked as 1 of steel matrix and precipitated on the matrix as a dis-
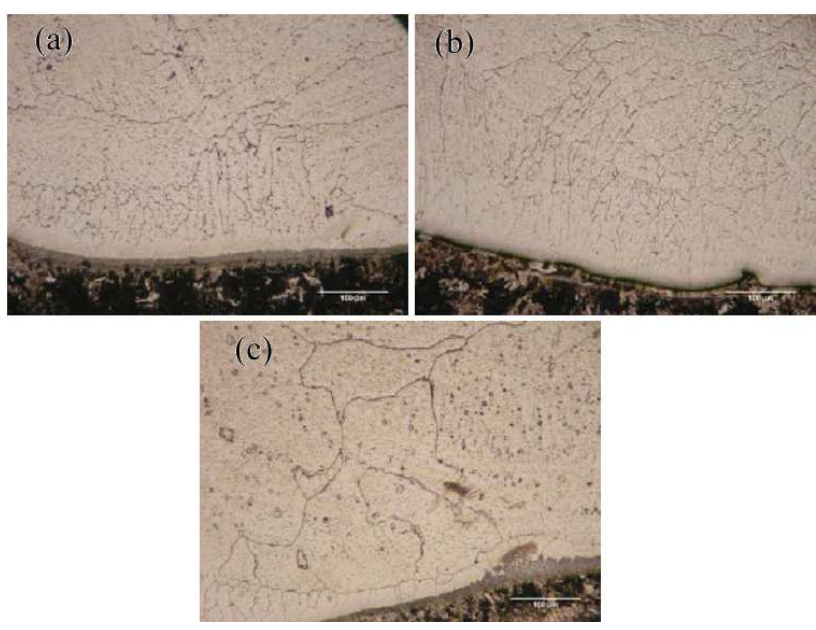

Fig. 2. Optical micrographs of the $\mathrm{Fe}_{(15-x)} \mathrm{Mo}_{x} \mathrm{~B}_{5}$ alloys for (a) $x=1$, (b) $x=3$, and (c) $x=5$.

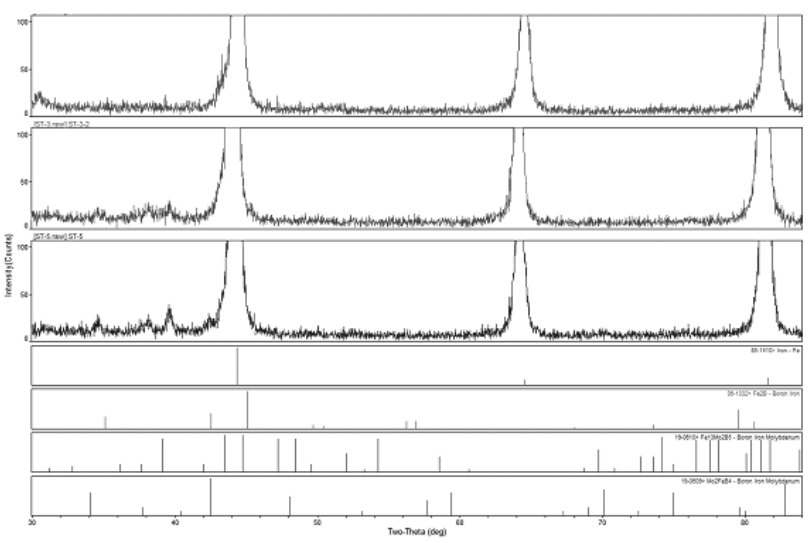

Fig. 3. X-ray diffraction analysis of $\mathrm{Fe}_{(15-x)} \mathrm{Mo}_{x} \mathrm{~B}_{5}$ alloys for $x=1,3$, and 5 .

persed structure, marked as 2 and steel matrix including molybdenum, marked as 3 in Fig. 4a. As shown from Fig. 4, the increase of molybdenum content in the alloy composition caused the increase of boride phases taking place in the alloyed layers. As seen in Fig. 4, borides formed in the in situ composite structure found in the alloyed layer two types of borides which were located on the grain boundaries and as dispersed phases in the matrix. The phases formed in the surface alloyed layers are supported by phase diagram of B-Fe-Mo [12] and Qin et al. [13]. Some parts of the alloyed layer have much more dense boride phase in the alloyed layer as seen in Fig. 4. Eroglu [14] and Bourithis et al. [15] studied the boron addition to the steel surface for surface alloying and they explained that the borides formed in the alloyed layer realized close up the grain boundaries. EDS analysis supports the X-ray diffraction analysis that the especially dispersed phases and grain boundary phases include much more molybdenum and boron beside the iron as shown in Fig. 4d-f. 

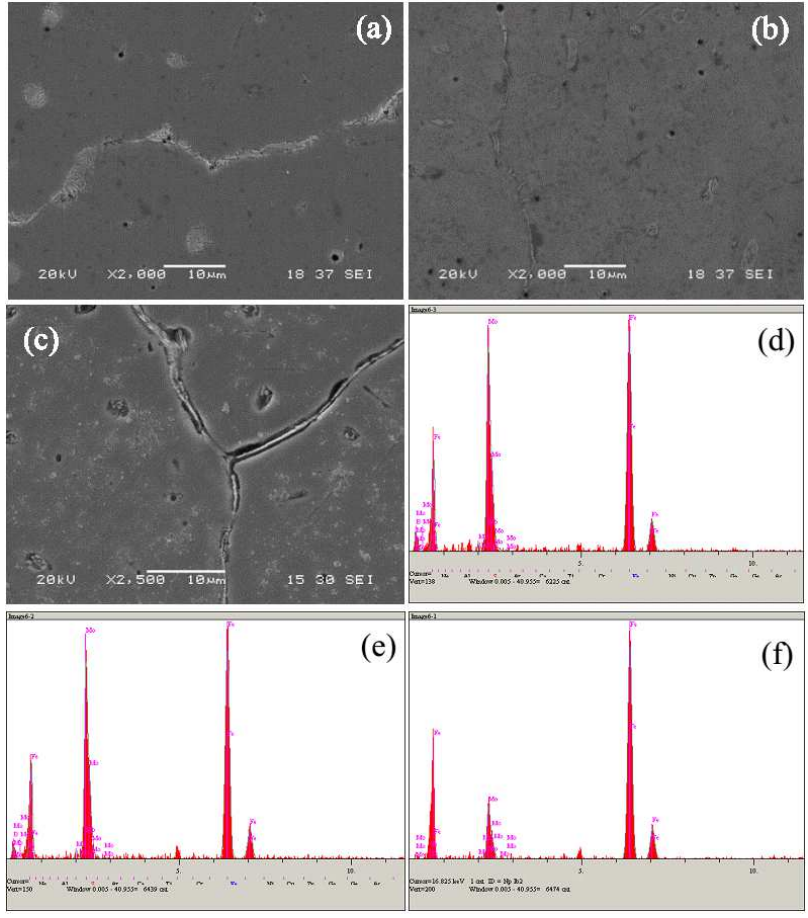

Fig. 4. SEM micrographs of the $\mathrm{Fe}_{(15-x)} \mathrm{Mo}_{x} \mathrm{~B}_{5}$, alloys for (a) $x=1$, (b) $x=3$ and (c) $x=5$, and (d) marked as 1, (e) marked as 2, and (f) marked as 3 on the micrograph of Fig. 4a, respectively.

Transition metal borides are the famous hard materials. The phases of molybdenum iron borides taking place in the alloyed layers are the hard phases. The mechanical properties of the alloyed layer increased with increase in boride phases. Therefore the addition of molybdenum caused the increase of the boride phase formation. As known, the hardness of transition metals ranged from $2000 \mathrm{HV}$ to $4000 \mathrm{HV}$ [16].

\section{Conclusions}

1. It has been proven that surface alloying treatment of AISI 1020 steel using by $\mathrm{Fe}_{(15-x)} \mathrm{Mo}_{x} \mathrm{~B}_{5}$ alloys for $x=1,3$, and 5 wear realized by TIG welding.

2. The alloyed surface layers were of smooth and rippled topography structure.
3. Surface alloyed layer consists of iron, boron, and molybdenum confirmed by EDS analysis and the melted surfaces of the surface alloyed steel present a smooth and rippled surface topography.

4. Hard faced layers of the steel consist of $\mathrm{Fe}_{2} \mathrm{~B}$, $\mathrm{Fe}_{13} \mathrm{Mo}_{2} \mathrm{~B}_{5}, \mathrm{Mo}_{2} \mathrm{FeB}_{4}$, and iron phases.

5 . Increase of the molybdenum content in the alloy composition caused the increase of boride phases formed in the alloyed layers.

\section{References}

[1] A.K. Chattopadhyay, L. Chollet, H.E. Hintermann, J. Mater. Sci. 26, 5093 (1991).

[2] Q.Y. Hou, J.S. Gao, F. Zhou, Surf. Coat. Technol. 194, 238 (2005).

[3] R.G. Wellman, J.R. Nicholls, Wear 242, 80 (2000).

[4] M. Eroglu, N. Ozdemir, Surf. Coat. Technol. 154, 209 (2002).

[5] K. Hyung-Jun, Y. Byoung-Hyun, L. Chang-Hee, Wear 249, 846 (2002).

[6] J.C. Ion, Laser Processing of Engineering Materials: Principles, Procedure and Industrial Application, Elsevier, Oxford 2005, p. 266.

[7] C. Fan, M.C. Chen, M.C. Chang, W. Wu, Surf. Coat. Technol. 201, 908 (2006).

[8] M. Zang, H. Wang, H. Wang, T. Cui, T. Cui, Y. Ma, J. Phys. Chem. C 114, 6722 (2010).

[9] U. Sen, S.S. Pazarlioglu, S. Sen, Mater. Lett., 2444 (2008).

[10] S.A. Kuznetsov, S.V. Kuznetsova, E.V. Rebrov, M.J.M. Mies, M.H.J.M. de Croon, J.C. Schouten, Surf. Coat. Technol. 195, 182 (2005).

[11] ASTM E407-07e1: Standard Practice for Microetching Metals and Alloys.

[12] V. Raghavan, J. Phase Equilibria 24, 449 (2003).

[13] L. Qin, K. Yang, C. Liu, B. Tang, Mater. Lett. 82, 127 (2012).

[14] M. Eroglu, Surf. Coat. Technol. 203, 2229 (2009).

[15] L. Bourithis, G. Papadimitriou, Mater. Lett. 57, 1835 (2003).

[16] B. Aronsson, T. Lundström, Borides, Silicides, and Phosphides: A Critical Review of Their Preparation, Properties and Crystal Chemistry, Methuen, London1965, p. 118. 